\title{
Consequences at adulthood of transient inactivation of the parahippocampal and prefrontal regions during early development: new insights from a disconnection animal model for schizophrenia
}

\author{
Francisca Meyer ${ }^{1 *}$ and Alain Louilot ${ }^{2 *}$ \\ ' Department of Molecular Animal Physiology, Donders Institute for Brain, Cognition and Behaviour, Radboud University Nijmegen, Nijmegen, Netherlands \\ ${ }^{2}$ INSERM U 1114, Faculty of Medicine, FMTS, University of Strasbourg, Strasbourg, France
}

\section{Edited by:}

Jean Zwiller, CNRS, France

Reviewed by:

Etienne Save, CNRS - Aix-Marseille

Université, France

Etienne Coutureau, CNRS/Université

de Bordeaux, France

*Correspondence:

Francisca Meyer, Department of Molecular Animal Physiology, Donders Institute for Brain, Cognition and Behavior, Radboud University Nijmegen, Geert Grooteplein Zuid 28, 6525 GA Nijmegen, Netherlands e-mail: F.Meyer@ncmls.ru.nl

Alain Louilot, INSERM U 1114, Faculty of Medicine, University of Strasbourg,

11 rue Humann, Strasbourg 67085,

France

e-mail: alain.louilot@unistra.fr
The psychic disintegration characteristic of schizophrenia is thought to result from a defective connectivity, of neurodevelopmental origin, between several integrative brain regions. The parahippocampal region and the prefrontal cortex are described as the main regions affected in schizophrenia. Interestingly, latent inhibition (LI) has been found to be reduced in patients with schizophrenia, and the existence of a dopaminergic dysfunction is also generally well accepted in this disorder. In the present review, we have integrated behavioral and neurochemical data obtained in a LI protocol involving adult rats subjected to neonatal functional inactivation of the entorhinal cortex, the ventral subiculum or the prefrontal cortex. The data discussed suggest a subtle and transient functional blockade during early development of the aforementioned brain regions is sufficient to induce schizophrenia-related behavioral and dopaminergic abnormalities in adulthood. In summary, these results support the view that our conceptual and methodological approach, based on functional disconnections, is valid for modeling some aspects of the pathophysiology of schizophrenia from a neurodevelopmental perspective.

Keywords: schizophrenia, animal modeling, neonatal functional inactivation, entorhinal cortex, ventral subiculum, prefrontal cortex, latent inhibition

\section{INTRODUCTION SCHIZOPHRENIA}

Schizophrenia is a complex neuropsychiatric disorder of unknown etiology, and its pathophysiology remains poorly understood. It affects about $1 \%$ of the population worldwide (Insel, 2010) and is a heavy burden not only for the families of the patients but also for society (Knapp et al., 2004; McEvoy, 2007). It was recently proposed that the characteristic psychic disintegration observed in schizophrenia would result from abnormal connectivity, i.e., disconnections, at least partly of neurodevelopmental origin (Weinberger and Lipska, 1995; Andreasen, 1999; Lewis and Levitt, 2002; Sawa and Snyder, 2002; Insel, 2010; Rapoport et al., 2012) between different integrative brain regions, especially the prefrontal cortex, the medial temporal lobe and striatal regions (Lawrie et al., 2002; Stephan et al., 2009; Meyer-Lindenberg, 2010; Fornito et al., 2011; Schmitt et al., 2011). This "disconnection hypothesis" in schizophrenia is backed up by a great many of neurophysiological and neuroimaging studies, but the cause of the dysconnectivity is still the subject of discussion. The current debate centers on two possible explanations, namely that the dysconnectivity may result from either (1) abnormal synaptic plasticity; or (2) abnormal white matter connections between two integrative brain regions (Friston, 1998, 1999; Stephan et al., 2006, 2009; for review see Shi et al., 2012). Both abnormal dendritic spine density (Glantz and Lewis, 2000; Black et al., 2004; Kolluri et al., 2005), and also myelination abnormalities (Du et al., 2013; Palaniyappan et al., 2013) have been reported in patients with schizophrenia. Early developmental abnormalities could lead to dopamine dysregulation (Murray et al., 2008; O’Donnell, 2011; Eyles et al., 2012) which ultimately results in the well-acknowledged dopaminergic imbalance observed in patients with schizophrenia (Meltzer and Stahl, 1976; Carlsson et al., 2001; Kuepper et al., 2012). Importantly, the prefrontal cortex and medial temporal lobe (i.e., entorhinal cortex, ventral subiculum) stand out as the main regions affected in schizophrenia. In this respect several cytoarchitectural and neuronal morphometric abnormalities have been described at the level of the prefrontal cortex (Garey, 2010; Yang et al., 2011; Nesvåg et al., 2012; Palaniyappan and Liddle, 2012), the entorhinal cortex (Arnold, 2000; Falkai et al., 2000; Prasad et al., 2004) and the ventral subiculum (Arnold, 2000; Rosoklija et al., 2000; Law et al., 2004). 


\section{NEURODEVELOPMENTAL ANIMAL MODELS FOR SCHIZOPHRENIA: FOCUS ON NEONATAL DISCONNECTION ANIMAL MODELS}

An accumulation of evidence over the past 20 years in favor of the neurodevelopmental hypothesis for schizophrenia has resulted in a number of animal models based on early impairment of brain development (for reviews see Weinberger, 1996; Rehn and Rees, 2005; Powell, 2010). It is not possible to present them all in this article, but, basically, these neurodevelopmental animal models for schizophrenia can be divided up into (i) epidemiological models; (ii) genetic models; and (iii) heuristic models. Epidemiological animal models are derived from studies which point to an increased risk of developing schizophrenia following perinatal exposure to environmental insults (e.g., isolation rearing, maternal deprivation, or postnatal exposure to stress, e.g., Ellenbroek et al., 2004; Lee et al., 2007; Amitai et al., 2013), infection or immune activation (Fruntes and Limosin, 2008; Meyer, 2014), nutritional deficiencies (Palmer et al., 2004; Harms et al., 2008), as well as obstetric complications (Boksa, 2004; Juarez et al., 2008). Recently developed genetic models are based on findings that implicate developmental candidate genes (e.g., Reelin, STOP, DISC1, NRG1) or human copy number variations (CNVs; e.g., 22q11.2 deletion; Chen et al., 2006; Powell et al., 2009; Fénelon et al., 2013), whereas heuristic models take account of a wider array of clinical and biological findings relevant to the pathophysiology of schizophrenia. Some of these heuristic models aim to reproduce cytoarchitectural abnormalities observed in schizophrenia and thus involve impaired neurogenesis based on the use of antimitotic agents such as methylazoxymethanol acetate (MAM; see Lodge and Grace, 2009) or cytosine arabinoside (Ara-C; Elmer et al., 2004) administered at the end of the gestational period, and more specifically at gestational day (GD) 17 or GD 19.5-20.5 respectively, a period corresponding to the end of the first trimester in humans (Clancy et al., 2001). One of the best-characterized neurodevelopmental animal models for schizophrenia is the neonatal ventral hippocampal lesion model (NVHL), which was initially developed to take account of anatomopathological data observed in the hippocampus of patients with schizophrenia (Lipska et al., 1993; Lipska and Weinberger, 1994; Lipska, 2004; Tseng et al., 2009). In this model, an excitotoxic lesion of the ventral hippocampus was performed at postnatal day 7 (PND7), which corresponds to the middle of the second trimester of gestation in humans (Clancy et al., 2001), considered to be a period of high vulnerability for developing schizophrenia (Weinberger and Lipska, 1995; Lewis and Levitt, 2002; Tseng et al., 2009). However, although the heuristic validity of this animal model is undeniable, it relies on massive and irreversible damage of the ventral hippocampus (Lipska et al., 1993; Fatemi and Folsom, 2009), whereas postmortem brain analyzes performed on schizophrenia patients have revealed only subtle anatomical alterations in the hippocampus, but no lesions or tracks of lesions (Harrison, 1999, 2004). Other neurodevelopmental models have been devised involving a neonatal excitotoxic lesion of another temporal region, the entorhinal cortex (Harich et al., 2008) or medial prefrontal cortex (Bennay et al., 2004; Schwabe et al., 2004, 2006; Enkel and Koch, 2009). However, as with the ventral hippocampus no lesions or tracks of lesions have been observed in these regions in patients with schizophrenia (Harrison, 1999). To overcome the construct validity weakness of lesion-based approaches (Lipska and Weinberger, 2000; Tseng et al., 2009), postnatal transient functional inactivation models have been designed as alternative models based on reversible neonatal functional blockade induced by local intracerebral infusion of tetrodotoxin (TTX), a wellknown blocker of voltage-sensitive sodium channels (Stevens et al., 2011). Electrical activity appears to be essential during neonatal brain development (Spitzer, 2006), and an interruption of impulse activity by TTX has been reported to have inhibitory effects on myelination (Demerens et al., 1996) and to disrupt the refinement of synaptic connections in target structures (Stryker and Harris, 1986; Katz and Shatz, 1996), as well as the normal maturing of dendritic spines (Drakew et al., 1999; Frotscher et al., 2000). Thus, the consequences of neonatal TTX inactivation appear to be adequate for modeling disconnections as proposed for schizophrenia (see above). Moreover, it has been shown that neonatal transient inactivation of the ventral hippocampus leads to schizophrenia-relevant features in adulthood, such as motor hyperactivity following a pharmacological (Damphetamine, MK-801) or environmental challenge (exposure to a novel environment; Lipska et al., 2002). Interestingly, in adult rats that underwent neonatal TTX inactivation of the ventral hippocampus, Brooks and co-workers reported deficient acetylcholine release from the prefrontal cortex following mesolimbic stimulation (Brooks et al., 2011), as well as deficits in a setshifting task (Brooks et al., 2012). In addition, results obtained in our laboratory, which are discussed in detail below, showed that neonatal transient TTX inactivation of the entorhinal cortex, ventral subiculum or prefrontal cortex induced disturbed dopaminergic and behavioral responses related to latent inhibition (LI) in adulthood (Peterschmitt et al., 2007; Meyer et al., 2009; Meyer and Louilot, 2011, 2012). It is important to note that no lesions or macroscopic anatomical changes have been observed in the aforementioned studies following neonatal TTX inactivation (Lipska et al., 2002; Peterschmitt et al., 2007; Meyer et al., 2009; Brooks et al., 2011; Meyer and Louilot, 2011, 2012; Brooks et al., 2012; Usun et al., 2013). Taken together, functional disconnection models appear to be a relevant conceptual approach to animal modeling for some aspects of the pathophysiology of schizophrenia and without inducing any major anatomical lesion.

\section{LATENT INHIBITION}

Some data point towards disturbed information processing in patients with schizophrenia. In this respect, the behavioral paradigms most widely used in schizophrenia research are LI and prepulse-inhibition of the startle reflex (PPI). Although both LI and PPI have been reported to be disrupted in acute schizophrenia patients (Baruch et al., 1988; Gray et al., 1995; Braff et al., 1999, 2001; Rascle et al., 2001; Kumari and Ettinger, 2010), whereas a contradictory view exists (Swerdlow, 2010), PPI is also impaired in a variety of other disorders such as Huntington's disease, Tourette's syndrome, temporal lobe epilepsy with psychosis, and post-traumatic stress disorder (Braff et al., 2001). By contrast, LI disruption appears more specific to schizophrenia (see Lubow and Weiner, 2010) and is a cognitive marker of choice for the animal 
modeling of schizophrenia. As first described by Lubow and Moore (Lubow and Moore, 1959), LI is a behavioral phenomenon observed in several animal species including humans (Lubow, 1989). It was originally defined as retarded acquisition of the conditioned response (CR) when the conditional stimulus (CS) is first pre-exposed on its own. It is generally accepted that LI allows for adaptations to be made to a changing environment. Despite the relative simplicity of the LI phenomenon, theoretical explanations have proved difficult. Since its discovery, different theories (see Lubow and Weiner, 2010) have been proposed, explaining it as (1) a defect in the acquisition of conditioning (attention/associability theories); (2) a switching mechanismcontrolled by the hippocampal formation-between the CSreinforcement associations acquired during conditioning and the CS-no event associations acquired during pre-exposure (Switching model); or (3) a defect in the expression of conditioning (retrieval theories). As for the neurobiological substrates of LI, lesion studies and in vivo neurochemical approaches (i.e., in vivo microdialysis, in vivo voltammetry) revealed the involvement of the mesencephalic dopaminergic systems (for review see Louilot et al., 2010) and in particular the dopaminergic neurons innervating the core and dorsomedian shell part of the nucleus accumbens - with the ventromedial shell involved in the affective perception of the stimulus (Jeanblanc et al., 2002) - as well as the anterior part of the dorsal striatum (Jeanblanc et al., 2003).

\section{DISRUPTED LATENT INHIBITION: A RECOGNITION MEMORY DEFICIT?}

The present review includes behavioral and neurochemical data recently obtained in a LI protocol involving adult rats subjected to early neonatal (postnatal day 8) functional TTX inactivation of the entorhinal cortex, ventral subiculum or prefrontal cortex (Peterschmitt et al., 2007; Meyer et al., 2009; Meyer and Louilot, 2011, 2012). We were able to show that subtle and transient functional inactivation of the aforementioned cerebral regions during early development is sufficient to induce schizophreniarelated behavioral abnormalities: disrupted LI accompanied by dopaminergic changes recorded during adulthood in the dorsal striatum and the core part of the nucleus accumbens (see summarizing Table 1). In the context of these studies, LI was measured in a three-stage paradigm involving a conditioned olfactory aversive procedure with banana odor as the conditional stimulus (CS) and lithium chloride $(\mathrm{LiCl})$, a nausea-induced toxic substance, as the unconditional stimulus (US; Jeanblanc et al., 2002; see Figure 1). This paradigm clearly allows for the observation of LI, as evidenced by the disappearance of the aversively conditioned behavioral response (i.e., aversion towards the CS) in the pre-exposed conditioned animals (see Jeanblanc et al., 2002; Peterschmitt et al., 2007; Louilot et al., 2010; Meyer and Louilot, 2011, 2012).

Interestingly, as regards the entorhinal cortex and ventral subiculum, the behavioral responses obtained following TTX inactivation of the two temporal regions performed at postnatal day 8 were similar or even stronger than those obtained following TTX inactivation of the same brain regions in adulthood prior to the pre-exposure session. Previous data obtained in adult animals suggested that both temporal regions are part of a system involved in the recognition memory of the stimulus (Jeanblanc et al., 2004; Peterschmitt et al., 2005, 2008). In this context, it is important to recall that in the past different theoretical constructs have been proposed as explanations for LI (see Lubow and Weiner, 2010). In short, it was initially suggested that LI reflects a delay in acquiring the conditioning relating to a learned inattention to the CS (see Lubow, 1989) or a decrease in CS associability (Mackintosh, 1975, 1983; Wagner, 1976) due to presentation of the CS alone during the pre-exposure session. Contrary to that, however, it has also been suggested that LI corresponds to a defect in the behavioral expression of conditioning which is normally acquired during the conditioning session (Miller and Matzel, 1988; Weiner, 1990, 2003; Kraemer et al., 1991; Bouton, 1993). Hypothesizing a failure in the expression of conditioning is an easier interpretation of the results obtained with our threestage LI paradigm (see Figure 1) than hypothesizing a defect in the acquisition of conditioning. First of all, these results, which show that in the retention session pre-exposed conditioned animals display a similar approach to the CS (banana odor) as pre-exposed control and non-pre-exposed control animals (Jeanblanc et al., 2002), suggest a similar interest in the CS, for the three groups and therefore do not support the hypothesis of a learned inattention to the stimulus in the pre-exposed conditioned group. Secondly, results obtained previously in the different subregions of the nucleus accumbens (Jeanblanc et al., 2002) showed that dopaminergic responses in the core and dorsomedial

Table 1 | Summary of the main results obtained at the behavioral and neurochemical level following neonatal TTX inactivation of the entorhinal cortex, the ventral subiculum or the prefrontal cortex.

\begin{tabular}{|c|c|c|c|c|}
\hline \multirow[t]{2}{*}{$\begin{array}{l}\text { Brain regions inactivated } \\
\text { at PND8 }\end{array}$} & \multirow[t]{2}{*}{$\begin{array}{l}\text { Reversal of behavioral } \\
\text { LI expression }\end{array}$} & \multicolumn{2}{|c|}{$\begin{array}{l}\text { Reversal of LI-related } \\
\text { dopaminergic responses }\end{array}$} & \multirow[t]{2}{*}{ References } \\
\hline & & Core & Dorsal striatum & \\
\hline Ventral subiculum & $\sqrt{ }$ & Partial & $\sqrt{ }$ & $\begin{array}{l}\text { Meyer et al. (2009); } \\
\text { Meyer and Louilot (2011) }\end{array}$ \\
\hline
\end{tabular}




\section{Latent Inhibition Paradigm}
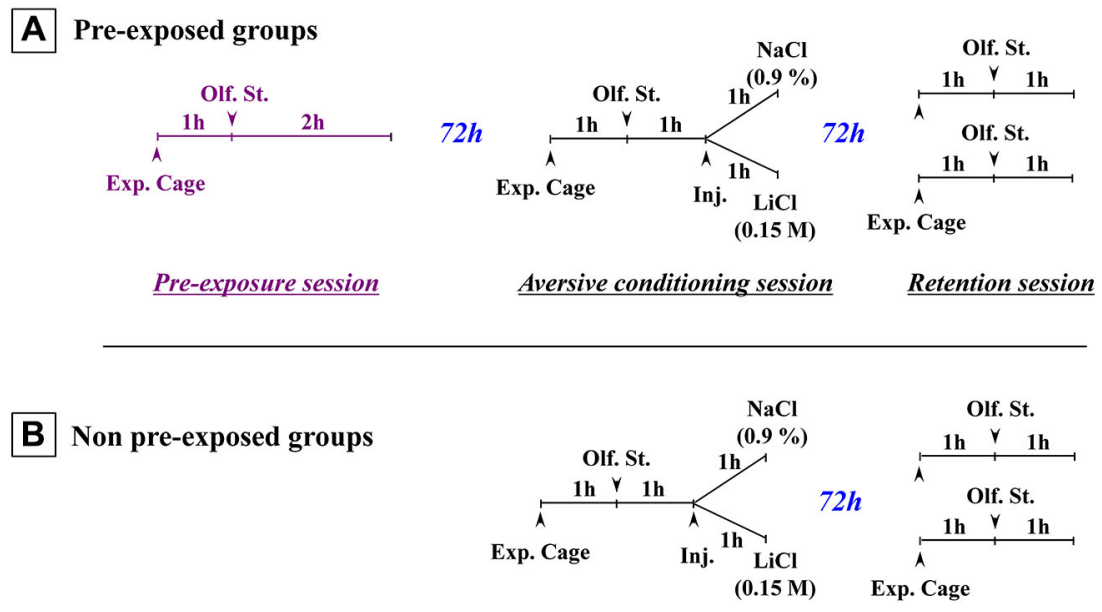

Aversive conditioning session Retention session

FIGURE 1 | Schematic representation of the paradigm used to obtain latent inhibition. (A) Three-stage latent inhibition paradigm. During the pre-exposure (first) session, the animals were placed in the experimental cage (Exp. Cage) for $1 \mathrm{~h}$ without any olfactory stimulus (Olf. St.), before being exposed to the to-be-conditioned olfactory stimulus (banana odor) for $2 \mathrm{~h} .72 \mathrm{~h}$ later, the animals were subjected to the conditioning (second) session. After a 1 -h period that allowed the rats to become accustomed to the experimental cage, they were then exposed to the banana odor (CS) for $1 \mathrm{~h}$. After that, they were given an intraperitoneal (i.p.) injection of either a saline $(\mathrm{NaCl} 0.9 \%)$ or an isotonic solution of $\mathrm{LiCl}(0.15 \mathrm{M})$. They then remained in the cage with the olfactory stimulus for a further hour. $72 \mathrm{~h}$ later, they were returned to the experimental cage for the test (third) session. After a 1-h familiarization period, they were exposed to the CS for a further hour. Their attraction or aversion towards the olfactory stimulus (banana odor) was then assessed in terms of how much time they spent near the olfactive source. The olfactory aversive conditioning protocol (B) was exactly the same except that non-pre-exposed animals were subjected only to the conditioning (second) session and the test (third) session (Adapted from Jeanblanc et al., 2002). shell parts of the nucleus accumbens are related to LI, whereas dopaminergic responses in the ventromedial shell part of the nucleus accumbens appear to be related only to conditioning, not LI, insofar as similar small dopaminergic increases were observed in this subregion in pre-exposed conditioned and nonpre-exposed conditioned groups whereas marked dopaminergic increases were observed in the two control groups. These latter results suggest aversive conditioning was normally acquired in pre-exposed conditionned animals but not behaviorally expressed during the retention (test) stage. This proposal is consistent with theoretical constructs which suggest differently that the expression of LI reflects interference or competition between the memories of the CS-alone or the CS-no event acquired during pre-exposure and the memory of the aversive valence related to the CS acquired during conditioning (Miller and Matzel, 1988; Bouton, 1993; see also Weiner, 2003; Louilot et al., 2010). In keeping with these explanations, in a heuristic perspective, one interpretation of the fact that conditioning is normally acquired but not expressed during the retention session would be that LI responses, at least in our LI paradigm, reflect the inhibitory influence a neuronal system involved in some kind of recognition memory of the CS alone or the CS-no event encoded during the pre-exposure session has upon a second neuronal system involved in the expression of aversive conditioning towards the CS (Jeanblanc et al., 2002). Past data suggest the basolateral nucleus of amygdala may be part of the second system (Louilot and Besson, 2000). To shore up our heuristic hypothesis regarding the system involved in recognition memory, we investigated in adult animals the consequences of functional inactivation of the entorhinal cortex and ventral subiculum, two structures described as being involved in both LI (Gray et al., 1995; Weiner and Feldon, 1997; Weiner, 2003) and recognition memory of olfactory stimuli (Suzuki and Eichenbaum, 2000; Petrulis et al., 2005; Eichenbaum et al., 2007). In so doing, we considered that if a structure is involved in encoding information during preexposure, it may also be involved in retrieving this information during the retention session. Thus, TTX inactivation of the entorhinal cortex and ventral subiculum was performed during the pre-exposure session, and the behavioral and dopaminergic responses were measured during the retention (third) session (Jeanblanc et al., 2004; Peterschmitt et al., 2005, 2008). A reversal of LI responses towards conditioned aversive responses was observed during this last session, lending support to the proposal that a neural system involved in recognition memory played a role in our LI paradigm. It is a proposal backed up by data obtained in a three-stage cued fear conditioning LI paradigm in adult mice following functional inactivation of the entorhinal/subicular region by muscimol (Lewis and Gould, 2007). More specifically, these authors showed that inactivation during the pre-exposure or retention session, but not conditioning session, causes the behavioral expression of LI to be lost during testing (see Peterschmitt et al., 2008, for an extensive discussion). 
Others have also suggested some kind of recognition memory is involved in LI, based on their findings in an inhibitory avoidance paradigm after cholinergic manipulation of the insular cortex at pre-exposure (Miranda and Bermúdez-Rattoni, 2007). In other words, there is support for the view that defective information retrieval related to the CS is involved in the disruption of LI. It is important to note here that (1) recognition memory defects have been reported in patients with schizophrenia (Danion et al., 1999; Huron and Danion, 2002; Pelletier et al., 2005; Drakeford et al., 2006; Danion et al., 2007; van Erp et al., 2008; Libby et al., 2013); and (2) numerous animals models for schizophrenia have shown deficits in novel object recognition tasks (e.g., Schneider and Koch, 2003; Brosda et al., 2011; McIntosh et al., 2013).

Regarding early neonatal TTX inactivation of temporal or prefrontal regions, a number of different mechanisms could account for the loss of behavioral LI expression observed in adulthood. It is well accepted that electrical activity plays an essential role in the early development of the nervous system (Spitzer, 2006) and is involved in a number of cellular processes, such as axons' myelination (Demerens et al., 1996), rearrangement of synaptic connections in target structures (Stryker and Harris, 1986; Katz and Shatz, 1996; Hutchins and Kalil, 2008), and maturation of dendritic spines (Drakew et al., 1999). Importantly, the first 2 postnatal weeks are known to be critical for the development of the parahippocampal regions and prefrontal cortex in rodents (Clancy et al., 2001). Indeed, several authors have reported that the connectivity of the parahippocampal region (i.e., entorhinal cortex and the ventral subiculum), but also of the prefrontal cortex, is still maturing during the second postnatal week (Schlessinger et al., 1975; Singh, 1977a,b; Fricke and Cowan, 1978; van Eden et al., 1990). Thus, following TTX neonatal inactivation, failure of one or more of the abovementioned mechanisms could result in abnormalities in the intrinsic and/or extrinsic connectivity of these brain structures. Through a combination of the aforementioned cellular mechanisms, early TTX inactivation could very well induce a functional disturbance of the entorhinal cortex and ventral subiculum, resulting in encoding defects of the CS but also a loss of recovery of information related to the CS which would manifest itself in adulthood in a malfunctioning recognition memory system, preventing proper learning and memorization of the characteristics related to the CS (banana odor) during preexposure to the stimulus (see discussion above; Louilot et al., 2010). Indeed, at adulthood, during the retention session, only the association between the CS and the negative reinforcement (malaise induced by $\mathrm{LiCl}$ ) that occurred during the conditioning phase would be retrieved. This would explain the expression of an aversive reaction to the stimulus-instead of an approach reaction typical of LI expression-in animals neonatally microinjected with TTX (Peterschmitt et al., 2007; Meyer et al., 2009).

Regarding the prefrontal cortex, the data we have obtained thus far after neonatal inactivation do not allow us to conclude whether or not this structure is involved in encoding the information related to the CS during pre-exposure and/or retrieval during the test phase (Meyer and Louilot, 2012). However, because of close anatomical connections between the prefrontal cortex and the entorhinal cortex and ventral subiculum (Jay et al., 1989; Jay and Witter, 1991; Carr and Sesack, 1996; Insausti et al., 1997; Heidbreder and Groenewegen, 2003; Hoover and Vertes, 2007), the prefrontal cortex may very well be part of the recognition memory system thought to be involved in the LI phenomenon and may thus be malfunctioning after early neonatal inactivation. The disappearance of LI behavior observed in animals subjected to neonatal TTX inactivation may also be related to neurodevelopmental disturbances in target regions of the prefrontal cortex that are secondary to the neonatal inactivation (e.g., myelination defects in projection structures, particularly the hippocampal regions), rather than to a functional impairment of the prefrontal cortex per se. Myelination defects have been observed after neonatal ibotenic lesion of the prefrontal cortex (Schneider and Koch, 2005; Klein et al., 2008) but have yet to be demonstrated following TTX postnatal blockade.

Taken together, the data obtained in our early life disconnection model show that neonatal transient blockade of the entorhinal cortex, ventral subiculum, or prefrontal cortex, all structures described as targets of neurodevelopmental disturbances in schizophrenia, disrupt the behavioral expression of LI in adulthood. Based on the experimental and clinical data set out above, it is tempting to propose that these early functional disconnections may induce neurodevelopmental abnormalities in the parahippocampal region and prefrontal cortex which lead in adulthood to a disruption of mnemonic processing abilities resulting in turn in an impaired recognition memory reflected in our animal model by a disruption of the behavioral expression of LI.

\section{DYSREGULATION OF THE STRIATAL LI-RELATED DOPAMINERGIC RESPONSES INVOLVEMENT OF THE PARAHIPPOCAMPAL REGION: ENTORHINAL CORTEX AND VENTRAL SUBICULUM (SEE SUMMARIZING FIGURE 2)}

We showed very interestingly that the reversal of the behavioral expression of LI following early inactivation of the entorhinal cortex, ventral subiculum or prefrontal cortex had different consequences for LI-related dopaminergic responses depending on the striatal region considered: ventral striatum or dorsal striatum (see summarizing Table 1). As a result of reciprocal connections between the entorhinal cortex and ventral subiculum (Van Groen and Lopes da Silva, 1986; Naber et al., 2000; van Groen et al., 2003; O'Mara, 2005) one would expect the entorhinal cortex and ventral subiculum to exert similar controls on dopaminergic responses at the level of the nucleus accumbens. However, our results showed that a neonatal functional blockade of the entorhinal cortex induced a complete loss of dopaminergic responses characteristic of LI recorded in the core part of the nucleus accumbens, but only a partial reversal of these responses in the dorsal striatum (Peterschmitt et al., 2007; Meyer et al., 2009). Neonatal inactivation of the ventral subiculum, on the other hand, caused partial loss of dopaminergic responses characteristic of LI in the core part and a total disappearance of these responses in the dorsal striatum (Meyer et al., 2009; Meyer and Louilot, 2011). It is clear from these results that the two medial temporal structures exercise a different control over dopaminergic 


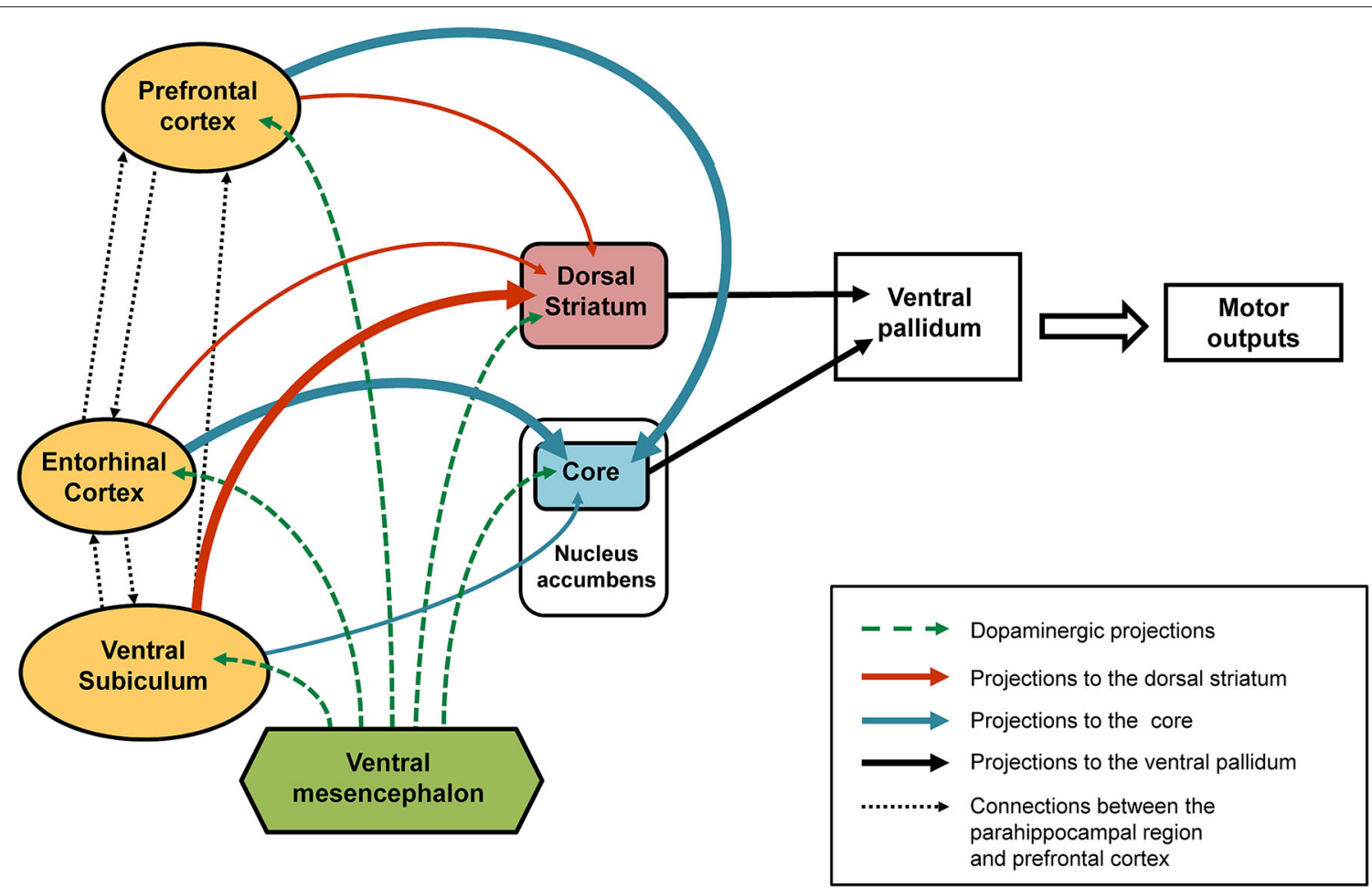

FIGURE 2 | Schematic representation of the connections affected following early-life (PND8) TTX inactivation. After TTX blockade of the entorhinal cortex, ventral subiculum or prefrontal cortex performed at PND8 a number of interconnected brain regions are affected (see solid arrows). Our data showed that the ventral subiculum exerts strong control over the dopaminergic responses recorded in the dorsal striatum (thick orange arrows) and only slightly affects the dopaminergic variations in the core part of the nucleus accumbens (thin blue arrow). By contrast, strong control over the dopaminergic responses recorded in the core (thick blue arrows) is exerted by the entorhinal cortex and the medial prefrontal cortex, whereas both these regions have little influence over the dopaminergic responses recorded in the dorsal striatum (thin orange arrows). The broken green arrows denote dopaminergic projections from the ventral mesencephalon. We propose that the behavioral responses observed in latent inhibition are the result of functional complementarity at the level of the ventral pallidum (dorsolateral part), of dopamineregulated efferents from the dorsal striatum and the core part of the nucleus accumbens
LI-related responses in the ventral and dorsal striatum. Connectivity differences may very well account for the stronger effect of a neonatal functional blockade of the entorhinal cortex on LIrelated dopaminergic responses recorded in the core part of the nucleus accumbens. Indeed, there is clear evidence for regulation of the dopaminergic transmission at the level of the nucleus accumbens by the entorhinal cortex, on the one hand (Louilot and Le Moal, 1994; Louilot and Choulli, 1997), and the ventral subiculum, on the other hand (Louilot and Le Moal, 1994; Blaha et al., 1997; Legault et al., 2000; Floresco et al., 2001; PelegRaibstein and Feldon, 2006). Secondly, the two parahippocampal regions project on the nucleus accumbens (McGeorge and Faull, 1989), although such projections are distributed unevenly, with a much denser innervation of the core part of the nucleus accumbens from the entorhinal cortex than from the ventral subiculum (Groenewegen et al., 1987; Brog et al., 1993; Totterdell and Meredith, 1997).

As for the dorsal striatum, it seems that, similar to the core part of the nucleus accumbens, the two temporal structures exert a distinct control over the LI-related dopaminergic responses recorded in the anterior part of the dorsal striatum, with a stronger effect induced by inactivation of the ventral subiculum. Although the interactions between the entorhinal cortex and ventral subiculum, with dopaminergic neurons innervating the anterior part of the dorsal striatum, have yet to be specified, known connections mainly originating in the entorhinal cortex and ventral subiculum have been described in the median part of the anterior dorsal striatum, which is where dopamine was measured in our own studies (Groenewegen et al., 1987; McGeorge and Faull, 1989; Finch et al., 1995; Finch, 1996; Totterdell and Meredith, 1997).

As regards the core part of the nucleus accumbens, a relationship was found in our behavioral paradigm between dopaminergic variations and the direction of behavioral responses (attraction or aversion) in animals not subjected to any neonatal functional blockade (Jeanblanc et al., 2002, 2004; Peterschmitt et al., 2008). Thus, it has been shown that the approach of the stimulus is accompanied by a marked increase in dopamine in the core part of the nucleus accumbens, while a rapid transient signal decrease and return to baseline values accompanies the response of avoidance. Results that support this view have been obtained during self-administration of cocaine (Phillips et al., 2003) in studies where the authors revealed gradual increases in extracellular dopamine levels in rats who were approaching the lever used to deliver cocaine and thus signaling reward, the 
suggestion being that dopaminergic variations recorded in the core part of the nucleus accumbens may precede the expression of behavioral responses. This interpretation is also consistent with the proposal that the core part of the nucleus accumbens is involved in the permutation or switching between different behavioral sequences so that there is an appropriate response is to the context, and in particular the LI phenomenon (Weiner and Feldon, 1997; Weiner, 2003). Concerning the dorsal striatum, it has also been shown that dopaminergic responses recorded in this region are in the same direction and similar to those found in the core part of the nucleus accumbens (Jeanblanc et al., 2003, 2004; Peterschmitt et al., 2005). However, the dopaminergic responses obtained after neonatal TTX inactivation of the entorhinal cortex and ventral subiculum suggest the relationship between dopaminergic changes in the core and the dorsal striatum and behavioral responses may be more complex than initially suggested. Indeed, pre-exposed conditioned animals that underwent neonatal inactivation of the ventral subiculum surprisingly displayed a small increase in dopamine in the core while displaying an aversion response (Peterschmitt et al., 2007; Meyer and Louilot, 2011). They were also characterized by no increase in dopamine in the anterior part of the dorsal striatum (Meyer et al., 2009). As previously discussed, in preexposed conditioned animals subjected to neonatal blockade of the entorhinal cortex an almost opposite dopaminergic profile is obtained in the two striatal regions while a similar behavioral expression is obtained. This important and very interesting finding prompts us to suggest that the lack of dopamine increase in one of the two striatal subregions-core or dorsal striatum-appears to be enough to disrupt the normal behavioral expression of LI. This proposal presupposes a functional similarity and complementarity between the core part of the nucleus accumbens and the adjacent part of the anterior dorsal striatum targeted in our studies. Several reports back the plausibility of this hypothesis. Based on anatomo-functional considerations, Voorn et al. (2004) have proposed that the striatum can be organized in parallel vertical columns encompassing the well-acknowledged ventral and dorsal striatal subdivisions. According to this scheme, the core part of the nucleus accumbens and anterior part of the dorsal striatum situated above the core are part of the same column (Voorn et al., 2004). Moreover, converging efferents from the core part of the nucleus accumbens and adjacent regions of the dorsal striatum close to the dorsolateral part of ventral pallidum have been described (Mogenson et al., 1983; Groenewegen et al., 1993), suggesting the coordinated involvement of the two striatal subregions in output responses, and namely motor responses. It is important to note here that the dorsolateral part of the ventral pallidum has been shown to send direct projections to the substantia nigra, pars reticulata (Groenewegen et al., 1993; see also Zahm, 2000). Our proposal, therefore, is that in LI-related responses there is a functional complementarity between the core and anterior dorsal striatum influences, at the level of the ventral pallidum (see summarizing Figure 2). In this context, it is interesting to note that Menon and colleagues (Menon et al., 2001) used functional magnetic resonance imaging (fMRI) to show a dysfunction of the basal ganglia and more specifically a lack of activation of the putamen and globus pallidus, the suggestion being that these structures are involved in behavioral disturbances in goal-directed actions observed in schizophrenia patients.

\section{INVOLVEMENT OF THE PREFRONTAL CORTEX (SEE SUMMARIZING FIGURE 2)}

Concerning the neonatal inactivation of the medial prefrontal cortex (infralimbic/prelimbic region), we showed that early and reversible functional inactivation of this region is sufficient to induce a complete loss of behavioral expression of LI as well as a complete disruption of LI-related dopaminergic responses in the core part of the nucleus accumbens (Meyer and Louilot, 2012) and partial loss of these responses in the anterior part of dorsal striatum (unpublished results; see summarizing Table 1). Therefore, these data argue in favor of involvement of the prefrontal cortex in the LI phenomenon, despite its involvement having been controversial for many years (Broersen et al., 1996; Ellenbroek et al., 1996; Joel et al., 1997; Lacroix et al., 1998; Broersen et al., 1999; Lacroix et al., 2000a,b). As mentioned above, the absence of LI in adult animals after postnatal TTX inactivation of the prefrontal cortex could be explained by different cellular mechanisms. Similar to previous studies, no gross anatomical changes were observed in either the prefrontal cortex, nucleus accumbens (Meyer and Louilot, 2012), or dorsal striatum (unpublished results). It is therefore possible to suggest that a transient blockade of the electrical activity in the prefrontal cortex during a critical period involves one or more mechanisms, permanently affecting communication between the prefrontal cortex and structures receiving direct projections such as the nucleus accumbens (Gorelova and Yang, 1997; Heidbreder and Groenewegen, 2003), structures that innervate the prefrontal cortex, such as the subiculum (Jay et al., 1989; Jay and Witter, 1991), or those sharing reciprocal connections with the prefrontal cortex, such as the entorhinal cortex (Insausti et al., 1997; Heidbreder and Groenewegen, 2003; Hoover and Vertes, 2007). As already discussed above, different cellular mechanisms may result in neuroanatomical changes responsible for poor integration of information in the prefrontal cortex resulting in changes in dopamine release in the core part of the nucleus accumbens or the dorsal striatum in pre-exposed conditioned animals subjected to TTX inactivation.

As regards the core part of the nucleus accumbens, it has been shown that dopaminergic transmission depends on the functional activity of the prefrontal cortex (Louilot et al., 1989). Moreover, the prefrontal cortex may control dopaminergic responses directly in the nucleus accumbens. Indeed, several authors have described projections from the infralimbic/prelimbic region of the prefrontal cortex to the core part of the nucleus accumbens (Berendse et al., 1992; Wright and Groenewegen, 1995; Gorelova and Yang, 1997). In addition, a close apposition has been described between efferents of the prefrontal cortex and dopaminergic endings in the nucleus accumbens (Sesack and Pickel, 1992). The prefrontal cortex may also indirectly regulate the activity of dopaminergic neurons reaching the nucleus accumbens via prefrontal efferences in the ventral tegmental area (Carr and Sesack, 2000). Concerning the dorsal striatum, several authors 
have also reported that striatal dopaminergic transmission is regulated by the prefrontal cortex (Jaskiw et al., 1990; Taber and Fibiger, 1993). It has been shown that there are projections from the infralimbic/prelimbic prefrontal region to the dorsal striatum (Montaron et al., 1996; Heidbreder and Groenewegen, 2003). A close proximity of prefronto-striatal projections and striatal dopaminergic terminals has also been described (Wang and Pickel, 2002). In addition, striatal dopaminergic transmission may be regulated indirectly by prefrontal projections in the substantia nigra (Heidbreder and Groenewegen, 2003). Given the similarities between the prefrontal and ventral and dorsal parts of the striatum in terms of anatomofunctional relationships, it is tempting tentatively to propose that differences in LI-related dopaminergic responses observed in the core part of the nucleus accumbens (complete reversal) and the anterior dorsal striatum (partial reversal) could be related to different functional relationships with another forebrain structure, namely the basolateral nucleus of the amygdala, which plays a crucial role in the control of dopaminergic response characteristics of conditioned aversion in the core part of the nucleus accumbens but does not appear to be involved in these dopaminergic responses in the dorsal striatum (Louilot and Besson, 2000). Importantly, convergence of afferents from the prefrontal cortex and the basolateral nucleus of the amygdala has been described in the nucleus accumbens (Wright and Groenewegen, 1995). Furthermore, amygdala regulation of dopaminergic transmission in the nucleus accumbens appears to be under the influence of the prefrontal cortex (Jackson and Moghaddam, 2001). To the best of our knowledge, such anatomomical and functional relationships have not been reported for the dorsal striatum. Ultimately, it is possible to propose that the disruption of LI-related dopaminergic responses observed following neonatal reversible TTX blockade of the prefrontal cortex could result, in adulthood, from an impairment of the control, mainly glutamatergic, exerted by the prefrontal cortex (Morari et al., 1998; David et al., 2005) over dopamine in the nucleus accumbens, by releasing the amygdalar regulation. However, the precise mechanisms of such disrupted control by the prefrontal cortex in LI following neonatal TTX inactivation are still unclear, given that the prefrontal cortex also seems to regulate the activity of dopaminergic neurons innervating the nucleus accumbens via cortical projections reaching the ventral tegmental area (Carr and Sesack, 2000). Finally, it cannot be excluded that LI-related dopaminergic variations in animals microinjected with TTX in the prefrontal cortex reflect also functional interactions with other forebrain regions, namely the entorhinal cortex and the ventral subiculum.

\section{SUMMARY AND CONCLUSIONS}

Taken together, functional disconnection neurodevelopmental models based on transient neonatal TTX inactivation are an attractive alternative to the NVHL model, since they result in schizophrenia-relevant features without anatomical lesions. Perinatal TTX inactivation consequences on myelination (Demerens et al., 1996), refinement of synaptic connections (Stryker and Harris, 1986; Katz and Shatz, 1996) and normal maturing of dendrites (Drakew et al., 1999; Frotscher et al., 2000) appear to be adequate for modeling disconnections as proposed for schizophrenia (see Section Introduction). Therefore, as regards the heuristic animal models for schizophrenia, postnatal TTX inactivation is an approach that presents a better construct validity. The data collected by our group showed that early functional blockade of the entorhinal cortex, ventral subiculum and prefrontal cortex structures reported in the literature as targets for neurodevelopmental disorders (see Akbarian et al., 1993a,b; Jakob and Beckmann, 1994; Weinberger et al., 1994; Goldman-Rakic and Selemon, 1997; Arnold, 2000; Falkai et al., 2000; Garey, 2010) results in the complete disappearance in adult animals of the LI phenomenon which in several studies has been found to be disrupted in acute patients with schizophrenia (Baruch et al., 1988; Gray et al., 1992, 1995; Lubow et al., 2000; Rascle et al., 2001; Young et al., 2005). Our findings suggest that the functional integrity of each of the three integrative structures is needed for normal expression of LI. We propose that the disappearance of LI behavioral and dopaminergic responses in our paradigm may be due to an impaired treatment of memories concerning the olfactory stimulus occurring at the time of pre-exposure and ultimately causing stimulus recognition in the retention phase and hence proper behavioral expression to be disrupted. Both parahippocampal regions, the entorhinal cortex and subiculum, as well as the medial prefrontal cortex could be part of a distributed system consisting of brain regions that are part of a system involved in stimulus recognition memory which interacts with another system involved in assigning an aversive valence to the stimulus. It is important to note here that a defect of recognition memory with recollection has been reported in patients with schizophrenia (Danion et al., 1999; Huron and Danion, 2002; Pelletier et al., 2005; Drakeford et al., 2006; Danion et al., 2007; van Erp et al., 2008; Libby et al., 2013). It is tempting to propose that neurodevelopmental defects of the same structures (temporal and prefrontal) result in a disruption of mnemonic processing capabilities and loss of LI expression in schizophrenia patients. One question still in abeyance is whether the abnormalities observed at the level of the entorhinal cortex, ventral subiculum or medial prefrontal cortex of patients with schizophrenia correspond to a group of patients or whether these defects can be observed in one and the same patient insofar as it would appear that there are no brain regions that have been found to be consistently affected in patients with schizophrenia (Goldman-Rakic and Selemon, 1997; Gur et al., 2007). Rather, the abnormalities are found in cortical or subcortical regions sharing connections with the prefrontal cortex. It would therefore be tempting to suggest that the expression of schizophrenia is the result of neurodevelopmental defects which occur in one of the cerebral regions that are part of the abovementioned recognition memory system but which engender specific dopamine changes depending on which brain region is affected. This could explain why schizophrenia manifests itself in some many different ways in patients with the disease.

Finally, recently obtained data showed that animals that underwent early-life inactivation of the prefrontal cortex also displayed greater behavioral and neurochemical reactivity to 
D-amphetamine (Meyer and Louilot, 2012) and ketamine, at subanesthetic doses (Usun et al., 2013). This is of particular interest given that both these drugs are known to induce psychotic symptoms in healthy individuals and to worsen such symptoms in patients with schizophrenia. Taken together, our findings give cause to consider that our conceptual and methodological approach, which integrates the hypothesis of functional disconnections stemming from neurodeveloppemental failures, is valid for modeling the pathophysiology of schizophrenia in animals and, more specifically, an interesting tool for modeling some of the cognitive deficits observed in the disease.

\section{ACKNOWLEDGMENTS}

The authors acknowledge support from INSERM \& Région Alsace, Fondation de France and the Faculty of Medicine (Francisca Meyer), and Electricité de France (EDF) (Alain Louilot).

\section{REFERENCES}

Akbarian, S., Bunney, W. E. Jr., Potkin, S. G., Wigal, S. B., Hagman, J. O., Sandman, C. A., et al. (1993a). Altered distribution of nicotinamide-adenine dinucleotide phosphate-diaphorase cells in frontal lobe of schizophrenics implies disturbances of cortical development. Arch. Gen. Psychiatry 50, 169-177. doi: 10. 1001/archpsyc. 1993.01820150007001

Akbarian, S., Viñuela, A., Kim, J. J., Potkin, S. G., Bunney, W. E. Jr., and Jones, E. G. (1993b). Distorted distribution of nicotinamide-adenine dinucleotide phosphate-diaphorase neurons in temporal lobe of schizophrenics implies anomalous cortical development. Arch. Gen. Psychiatry 50, 178-187. doi: 10. 1001/archpsyc.1993.01820150016002

Amitai, N., Young, J. W., Higa, K., Sharp, R. F., Geyer, M. A., and Powell, S. B. (2013). Isolation rearing effects on probabilistic learning and cognitive flexibility in rats. Cogn. Affect. Behav. Neurosci. doi: 10.3758/s13415-013-0204-4. [Epub ahead of print].

Andreasen, N. C. (1999). A unitary model of schizophrenia: Bleuler's "fragmented phrene" as schizencephaly. Arch. Gen. Psychiatry 56, 781-787. doi: 10. 1001/archpsyc.56.9.781

Arnold, S. E. (2000). Cellular and molecular neuropathology of the parahippocampal region in schizophrenia. Ann. N Y Acad. Sci. 911, 275-292. doi: 10.1111/j. 1749-6632.2000.tb06732.x

Baruch, I., Hemsley, D. R., and Gray, J. A. (1988). Differential performance of acute and chronic schizophrenics in a latent inhibition task. J. Nerv. Ment. Dis. 176, 598-606. doi: 10.1097/00005053-198810000-00004

Bennay, M., Gernert, M., Schwabe, K., Enkel, T., and Koch, M. (2004). Neonatal medial prefrontal cortex lesion enhances the sensitivity of the mesoaccumbal dopamine system. Eur. J. Neurosci. 19, 3277-3290. doi: 10.1111/j.0953-816x. 2004.03442.x

Berendse, H. W., Galis-de Graaf, Y., and Groenewegen, H. J. (1992). Topographical organization and relationship with ventral striatal compartments of prefrontal corticostriatal projections in the rat. J. Comp. Neurol. 316, 314-347. doi: 10. 1002/cne.903160305

Black, J. E., Kodish, I. M., Grossman, A. W., Klintsova, A. Y., Orlovskaya, D., Vostrikov, V., et al. (2004). Pathology of layer V pyramidal neurons in the prefrontal cortex of patients with schizophrenia. Am. J. Psychiatry 161, 742-744. doi: 10.1176/appi.ajp.161.4.742

Blaha, C. D., Yang, C. R., Floresco, S. B., Barr, A. M., and Phillips, A. G. (1997). Stimulation of the ventral subiculum of the hippocampus evokes glutamate receptor-mediated changes in dopamine efflux in the rat nucleus accumbens. Eur. J. Neurosci. 9, 902-911. doi: 10.1111/j.1460-9568.1997.tb01441.x

Boksa, P. (2004). Animal models of obstetric complications in relation to schizophrenia. Brain Res. Brain Res. Rev. 45, 1-17. doi: 10.1016/j.brainresrev. 2004.01.001

Bouton, M. E. (1993). Context, time, and memory retrieval in the interference paradigms of Pavlovian learning. Psychol. Bull. 114, 80-99. doi: 10.1037//00332909.114.1.80

Braff, D. L., Geyer, M. A., and Swerdlow, N. R. (2001). Human studies of prepulse inhibition of startle: normal subjects, patient groups, and pharmacological studies. Psychopharmacology (Berl) 156, 234-258. doi: 10.1007/s0021301 00810

Braff, D. L., Swerdlow, N. R., and Geyer, M. A. (1999). Symptom correlates of prepulse inhibition deficits in male schizophrenic patients. Am. J. Psychiatry 156, 596-602.

Broersen, L. M., Feldon, J., and Weiner, I. (1999). Dissociative effects of apomorphine infusions into the medial prefrontal cortex of rats on latent inhibition, prepulse inhibition and amphetamine-induced locomotion. Neuroscience 94, 39-46. doi: 10.1016/s0306-4522(99)00287-0

Broersen, L. M., Heinsbroek, R. P., de Bruin, J. P., and Olivier, B. (1996). Effects of local application of dopaminergic drugs into the medial prefrontal cortex of rats on latent inhibition. Biol. Psychiatry 40, 1083-1090. doi: 10.1016/S00063223(95)00595-1

Brog, J. S., Salyapongse, A., Deutch, A. Y., and Zahm, D. S. (1993). The patterns of afferent innervation of the core and shell in the "accumbens" part of the rat ventral striatum: immunohistochemical detection of retrogradely transported fluoro-gold. J. Comp. Neurol. 338, 255-278. doi: 10.1002/cne.903380209

Brooks, J. M., Pershing, M. L., Thomsen, M. S., Mikkelsen, J. D., Sarter, M., and Bruno, J. P. (2012). Transient inactivation of the neonatal ventral hippocampus impairs attentional set-shifting behavior: reversal with an $\alpha 7$ nicotinic agonist. Neuropsychopharmacology 37, 2476-2486. doi: 10.1038/npp.2012.106

Brooks, J. M., Sarter, M., and Bruno, J. P. (2011). Transient inactivation of the neonatal ventral hippocampus permanently disrupts the mesolimbic regulation of prefrontal cholinergic transmission: implications for schizophrenia. Neuropsychopharmacology 36, 2477-2487. doi: 10.1038/npp.2011.136

Brosda, J., Dietz, F., and Koch, M. (2011). Impairment of cognitive performance after reelin knockdown in the medial prefrontal cortex of pubertal or adult rats. Neurobiol. Dis. 44, 239-247. doi: 10.1016/j.nbd.2011.07.008

Carlsson, A., Waters, N., Holm-Waters, S., Tedroff, J., Nilsson, M., and Carlsson, M. L. (2001). Interactions between monoamines, glutamate, and GABA in schizophrenia: new evidence. Annu. Rev. Pharmacol. Toxicol. 41, 237-260. doi: 10.1146/annurev.pharmtox.41.1.237

Carr, D. B., and Sesack, S. R. (1996). Hippocampal afferents to the rat prefrontal cortex: synaptic targets and relation to dopamine terminals. J. Comp. Neurol. 369, 1-15. doi: 10.1002/(SICI) 1096-9861(19960520)369:1 < 1::AID-CNE1 > 3.0. $\mathrm{CO} ; 2-7$

Carr, D. B., and Sesack, S. R. (2000). Projections from the rat prefrontal cortex to the ventral tegmental area: target specificity in the synaptic associations with mesoaccumbens and mesocortical neurons. J. Neurosci. 20, 3864-3873.

Chen, J., Lipska, B. K., and Weinberger, D. R. (2006). Genetic mouse models of schizophrenia: from hypothesis-based to susceptibility gene-based models. Biol. Psychiatry 59, 1180-1188. doi: 10.1016/j.biopsych.2006.02.024

Clancy, B., Darlington, R. B., and Finlay, B. L. (2001). Translating developmental time across mammalian species. Neuroscience 105, 7-17. doi: 10.1016/s03064522(01)00171-3

Danion, J. M., Huron, C., Vidailhet, P., and Berna, F. (2007). Functional mechanisms of episodic memory impairment in schizophrenia. Can. J. Psychiatry 52, 693-701.

Danion, J. M., Rizzo, L., and Bruant, A. (1999). Functional mechanisms underlying impaired recognition memory and conscious awareness in patients with schizophrenia. Arch. Gen. Psychiatry 56, 639-644. doi: 10.1001/archpsyc.56. 7.639

David, H. N., Ansseau, M., and Abraini, J. H. (2005). Dopamine-glutamate reciprocal modulation of release and motor responses in the rat caudate-putamen and nucleus accumbens of "intact" animals. Brain Res. Brain Res. Rev. 50, 336-360. doi: 10.1016/j.brainresrev.2005.09.002

Demerens, C., Stankoff, B., Logak, M., Anglade, P., Allinquant, B., Couraud, F., et al. (1996). Induction of myelination in the central nervous system by electrical activity. Proc. Natl. Acad. Sci. U S A 93, 9887-9892. doi: 10.1073/pnas.93.18. 9887

Drakeford, J. L., Edelstyn, N. M., Oyebode, F., Srivastava, S., Calthorpe, W. R., and Mukherjee, T. (2006). Auditory recognition memory, conscious recollection, and executive function in patients with schizophrenia. Psychopathology 39, 199208. doi: $10.1159 / 000093524$

Drakew, A., Frotscher, M., and Heimrich, B. (1999). Blockade of neuronal activity alters spine maturation of dentate granule cells but not their dendritic arborization. Neuroscience 94, 767-774. doi: 10.1016/s0306-4522(99)00378-4

Du, F., Cooper, A. J., Thida, T., Shinn, A. K., Cohen, B. M., and Ongur, D. (2013). Myelin and axon abnormalities in schizophrenia measured with magnetic 
resonance imaging techniques. Biol. Psychiatry 74, 451-457. doi: 10.1016/j. biopsych.2013.03.003

Eichenbaum, H., Yonelinas, A. P., and Ranganath, C. (2007). The medial temporal lobe and recognition memory. Annu. Rev. Neurosci. 30, 123-152. doi: 10. 1146/annurev.neuro.30.051606.094328

Ellenbroek, B. A., Budde, S., and Cools, A. R. (1996). Prepulse inhibition and latent inhibition: the role of dopamine in the medial prefrontal cortex. Neuroscience 75, 535-542. doi: 10.1016/0306-4522(96)00307-7

Ellenbroek, B. A., de Bruin, N. M., van Den Kroonenburg, P. T., van Luijtelaar, E. L., and Cools, A. R. (2004). The effects of early maternal deprivation on auditory information processing in adult Wistar rats. Biol. Psychiatry 55, 701-707. doi: 10. 1016/j.biopsych.2003.10.024

Elmer, G. I., Sydnor, J., Guard, H., Hercher, E., and Vogel, M. W. (2004). Altered prepulse inhibition in rats treated prenatally with the antimitotic Ara-C: an animal model for sensorimotor gating deficits in schizophrenia. Psychopharmacology (Berl) 174, 177-189. doi: 10.1007/s00213-003-1757-7

Enkel, T., and Koch, M. (2009). Chronic corticosterone treatment impairs trace conditioning in rats with a neonatal medial prefrontal cortex lesion. Behav. Brain Res. 203, 173-179. doi: 10.1016/j.bbr.2009.04.033

Eyles, D., Feldon, J., and Meyer, U. (2012). Schizophrenia: do all roads lead to dopamine or is this where they start? Evidence from two epidemiologically informed developmental rodent models. Transl. Psychiatry 2:e81. doi: 10. 1038/tp.2012.6

Falkai, P., Schneider-Axmann, T., and Honer, W. G. (2000). Entorhinal cortex pre-alpha cell clusters in schizophrenia: quantitative evidence of a developmental abnormality. Biol. Psychiatry 47, 937-943. doi: 10.1016/s0006-3223(99) 00250-4

Fatemi, S. H., and Folsom, T. D. (2009). The neurodevelopmental hypothesis of schizophrenia, revisited. Schizophr. Bull. 35, 528-548. doi: 10.1093/schbul/ $\operatorname{sbn} 187$

Fénelon, K., Xu, B., Lai, C. S., Mukai, J., Markx, S., Stark, K. L., et al. (2013). The pattern of cortical dysfunction in a mouse model of a schizophrenia-related microdeletion. J. Neurosci. 33, 14825-14839. doi: 10.1523/jneurosci.1611-13. 2013

Finch, D. M. (1996). Neurophysiology of converging synaptic inputs from the rat prefrontal cortex, amygdala, midline thalamus, and hippocampal formation onto single neurons of the caudate/putamen and nucleus accumbens. Hippocampus 6, 495-512. doi: 10.1002/(SICI)1098-1063(1996)6:5\%3C495::AIDHIPO3\%3E3.3.CO;2-I

Finch, D. M., Gigg, J., Tan, A. M., and Kosoyan, O. P. (1995). Neurophysiology and neuropharmacology of projections from entorhinal cortex to striatum in the rat. Brain Res. 670, 233-247. doi: 10.1016/0006-8993(94)01279-q

Floresco, S. B., Todd, C. L., and Grace, A. A. (2001). Glutamatergic afferents from the hippocampus to the nucleus accumbens regulate activity of ventral tegmental area dopamine neurons. J. Neurosci. 21, 4915-4922.

Fornito, A., Yoon, J., Zalesky, A., Bullmore, E. T., and Carter, C. S. (2011). General and specific functional connectivity disturbances in first-episode schizophrenia during cognitive control performance. Biol. Psychiatry 70, 64-72. doi: 10.1016/j. biopsych.2011.02.019

Fricke, R., and Cowan, W. M. (1978). An autoradiographic study of the commissural and ipsilateral hippocampo-dentate projections in the adult rat. J. Comp. Neurol. 181, 253-269. doi: 10.1002/cne.901810204

Friston, K. J. (1998). The disconnection hypothesis. Schizophr. Res. 30, 115-125. doi: 10.1016/S0920-9964(97)00140-0

Friston, K. J. (1999). Schizophrenia and the disconnection hypothesis. Acta. Psychiatr. Scand. Suppl. 395, 68-79. doi: 10.1111/j.1600-0447.1999.tb05985.x

Frotscher, M., Drakew, A., and Heimrich, B. (2000). Role of afferent innervation and neuronal activity in dendritic development and spine maturation of fascia dentata granule cells. Cereb. Cortex 10, 946-951. doi: 10.1093/cercor/10.10.946

Fruntes, V., and Limosin, F. (2008). Schizophrenia and viral infection during neurodevelopment: a pathogenesis model? Med. Sci. Monit. 14, RA71-RA77.

Garey, L. (2010). When cortical development goes wrong: schizophrenia as a neurodevelopmental disease of microcircuits. J. Anat. 217, 324-333. doi: 10. 1111/j.1469-7580.2010.01231.x

Glantz, L. A., and Lewis, D. A. (2000). Decreased dendritic spine density on prefrontal cortical pyramidal neurons in schizophrenia. Arch. Gen. Psychiatry 57, 65-73. doi: 10.1001/archpsyc.57.1.65
Goldman-Rakic, P. S., and Selemon, L. D. (1997). Functional and anatomical aspects of prefrontal pathology in schizophrenia. Schizophr. Bull. 23, 437-458. doi: $10.1093 /$ schbul/23.3.437

Gorelova, N., and Yang, C. R. (1997). The course of neural projection from the prefrontal cortex to the nucleus accumbens in the rat. Neuroscience 76, 689-706. doi: 10.1016/s0306-4522(96)00380-6

Gray, N. S., Pickering, A. D., Hemsley, D. R., Dawling, S., and Gray, J. A. (1992). Abolition of latent inhibition by a single $5 \mathrm{mg}$ dose of d-amphetamine in man. Psychopharmacology (Berl) 107, 425-430. doi: 10.1007/bf02245170

Gray, N. S., Pilowsky, L. S., Gray, J. A., and Kerwin, R. W. (1995). Latent inhibition in drug naive schizophrenics: relationship to duration of illness and dopamine D2 binding using SPET. Schizophr. Res. 17, 95-107. doi: 10. 1016/0920-9964(95)00034-j

Groenewegen, H. J., Berendse, H. W., and Haber, S. N. (1993). Organization of the output of the ventral striatopallidal system in the rat: ventral pallidal efferents. Neuroscience 57, 113-142. doi: 10.1016/0306-4522(93)90115-v

Groenewegen, H. J., Vermeulen-Van der Zee, E., te Kortschot, A., and Witter, M. P. (1987). Organization of the projections from the subiculum to the ventral striatum in the rat. A study using anterograde transport of Phaseolus vulgaris leucoagglutinin. Neuroscience 23, 103-120. doi: 10.1016/0306-4522(87) 90275-2

Gur, R. E., Keshavan, M. S., and Lawrie, S. M. (2007). Deconstructing psychosis with human brain imaging. Schizophr. Bull. 33, 921-931. doi: 10. 1093/schbul/sbm045

Harich, S., Kinfe, T., Koch, M., and Schwabe, K. (2008). Neonatal lesions of the entorhinal cortex induce long-term changes of limbic brain regions and maze learning deficits in adult rats. Neuroscience 153, 918-928. doi: 10.1016/j. neuroscience.2008.03.017

Harms, L. R., Eyles, D. W., Mcgrath, J. J., Mackay-Sim, A., and Burne, T. H. (2008). Developmental vitamin D deficiency alters adult behaviour in 129/SvJ and C57BL/6J mice. Behav. Brain Res. 187, 343-350. doi: 10.1016/j.bbr.2007. 09.032

Harrison, P. J. (1999). The neuropathology of schizophrenia. A critical review of the data and their interpretation. Brain 122(Pt. 4), 593-624. doi: 10.1093/brain/122. 4.593

Harrison, P. J. (2004). The hippocampus in schizophrenia: a review of the neuropathological evidence and its pathophysiological implications. Psychopharmacology (Berl) 174, 151-162. doi: 10.1007/s00213-003-1761-y

Heidbreder, C. A., and Groenewegen, H. J. (2003). The medial prefrontal cortex in the rat: evidence for a dorso-ventral distinction based upon functional and anatomical characteristics. Neurosci. Biobehav. Rev. 27, 555-579. doi: 10.1016/j. neubiorev.2003.09.003

Hoover, W. B., and Vertes, R. P. (2007). Anatomical analysis of afferent projections to the medial prefrontal cortex in the rat. Brain Struct. Funct. 212, 149-179. doi: 10.1007/s00429-007-0150-4

Huron, C., and Danion, J. M. (2002). Impairment of constructive memory in schizophrenia. Int. Clin. Psychopharmacol. 17, 127-133. doi: 10.1097/00004850200205000-00006

Hutchins, B. I., and Kalil, K. (2008). Differential outgrowth of axons and their branches is regulated by localized calcium transients. J. Neurosci. 28, 143-153. doi: 10.1523/JNEUROSCI.4548-07.2008

Insausti, R., Herrero, M. T., and Witter, M. P. (1997). Entorhinal cortex of the rat: cytoarchitectonic subdivisions and the origin and distribution of cortical efferents. Hippocampus 7, 146-183. doi: 10.1002/(sici)10981063(1997)7:2<146::aid-hipo4>3.0.co;2-1

Insel, T. R. (2010). Rethinking schizophrenia. Nature 468, 187-193. doi: 10. 1038/nature09552

Jackson, M. E., and Moghaddam, B. (2001). Amygdala regulation of nucleus accumbens dopamine output is governed by the prefrontal cortex. J. Neurosci. 21, 676-681.

Jakob, H., and Beckmann, H. (1994). Circumscribed malformation and nerve cell alterations in the entorhinal cortex of schizophrenics. Pathogenetic and clinical aspects. J. Neural Transm. Gen. Sect. 98, 83-106. doi: 10.1007/bf01277013

Jaskiw, G. E., Karoum, F., Freed, W. J., Phillips, I., Kleinman, J. E., and Weinberger, D. R. (1990). Effect of ibotenic acid lesions of the medial prefrontal cortex on amphetamine-induced locomotion and regional brain catecholamine concentrations in the rat. Brain Res. 534, 263-272. doi: 10.1016/0006-8993(90)90138-2 
Jay, T. M., Glowinski, J., and Thierry, A. M. (1989). Selectivity of the hippocampal projection to the prelimbic area of the prefrontal cortex in the rat. Brain Res. 505, 337-340. doi: 10.1016/0006-8993(89)91464-9

Jay, T. M., and Witter, M. P. (1991). Distribution of hippocampal CA1 and subicular efferents in the prefrontal cortex of the rat studied by means of anterograde transport of Phaseolus vulgaris-leucoagglutinin. J. Comp. Neurol. 313, 574-586. doi: 10.1002/cne.903130404

Jeanblanc, J., Hoeltzel, A., and Louilot, A. (2002). Dissociation in the involvement of dopaminergic neurons innervating the core and shell subregions of the nucleus accumbens in latent inhibition and affective perception. Neuroscience 111, 315-323. doi: 10.1016/s0306-4522(02)00019-2

Jeanblanc, J., Hoeltzel, A., and Louilot, A. (2003). Differential involvement of dopamine in the anterior and posterior parts of the dorsal striatum in latent inhibition. Neuroscience 118, 233-241. doi: 10.1016/s0306-4522(02)00823-0

Jeanblanc, J., Peterschmitt, Y., Hoeltzel, A., and Louilot, A. (2004). Influence of the entorhinal cortex on accumbal and striatal dopaminergic responses in a latent inhibition paradigm. Neuroscience 128, 187-200. doi: 10.1016/j.neuroscience. 2004.06.022

Joel, D., Weiner, I., and Feldon, J. (1997). Electrolytic lesions of the medial prefrontal cortex in rats disrupt performance on an analog of the Wisconsin Card Sorting Test, but do not disrupt latent inhibition: implications for animal models of schizophrenia. Behav. Brain Res. 85, 187-201. doi: 10.1016/s01664328(97)87583-3

Juarez, I., Gratton, A., and Flores, G. (2008). Ontogeny of altered dendritic morphology in the rat prefrontal cortex, hippocampus, and nucleus accumbens following Cesarean delivery and birth anoxia. J. Comp. Neurol. 507, 1734-1747. doi: $10.1002 /$ cne. 21651

Katz, L. C., and Shatz, C. J. (1996). Synaptic activity and the construction of cortical circuits. Science 274, 1133-1138. doi: 10.1126/science.274.5290.1133

Klein, S., Koch, M., and Schwabe, K. (2008). Neuroanatomical changes in the adult rat brain after neonatal lesion of the medial prefrontal cortex. Exp. Neurol. 209, 199-212. doi: 10.1016/j.expneurol.2007.09.015

Knapp, M., Mangalore, R., and Simon, J. (2004). The global costs of schizophrenia. Schizophr. Bull. 30, 279-293. doi: 10.1093/oxfordjournals.schbul.a007078

Kolluri, N., Sun, Z., Sampson, A. R., and Lewis, D. A. (2005). Lamina-specific reductions in dendritic spine density in the prefrontal cortex of subjects with schizophrenia. Am. J. Psychiatry 162, 1200-1202. doi: 10.1176/appi.ajp.162.6. 1200

Kraemer, P. J., Randall, C. K., and Carbary, T. J. (1991). Release from latent inhibition with delayed testing. Anim. Learn. Behav. 19, 139-145. doi: 10. 3758/bf03197869

Kuepper, R., Skinbjerg, M., and Abi-Dargham, A. (2012). The dopamine dysfunction in schizophrenia revisited: new insights into topography and course. Handb. Exp. Pharmacol. 212, 1-26. doi: 10.1007/978-3-642-25761-2_1

Kumari, V., and Ettinger, U. (2010). "Latent inhibition in schizophrenia and schizotypy: a review of the empirical literature," in Latent Inhibition: Cognition, Neuroscience and Applications to Schizophrenia, eds R. E. Lubow and I. Weiner (New York: Cambridge University Press), 419-447.

Lacroix, L., Broersen, L. M., Feldon, J., and Weiner, I. (2000a). Effects of local infusions of dopaminergic drugs into the medial prefrontal cortex of rats on latent inhibition, prepulse inhibition and amphetamine induced activity. Behav. Brain Res. 107, 111-121. doi: 10.1016/s0166-4328(99)00118-7

Lacroix, L., Broersen, L. M., Weiner, I., and Feldon, J. (1998). The effects of excitotoxic lesion of the medial prefrontal cortex on latent inhibition, prepulse inhibition, food hoarding, elevated plus maze, active avoidance and locomotor activity in the rat. Neuroscience 84, 431-442. doi: 10.1016/s0306-4522(97) 00521-6

Lacroix, L., Spinelli, S., Broersen, L. M., and Feldon, J. (2000b). Blockade of latent inhibition following pharmacological increase or decrease of GABA(A) transmission. Pharmacol. Biochem. Behav. 66, 893-901. doi: 10.1016/s00913057(00)00269-0

Law, A. J., Weickert, C. S., Hyde, T. M., Kleinman, J. E., and Harrison, P. J. (2004). Reduced spinophilin but not microtubule-associated protein 2 expression in the hippocampal formation in schizophrenia and mood disorders: molecular evidence for a pathology of dendritic spines. Am. J. Psychiatry 161, 1848-1855. doi: 10.1176/appi.ajp.161.10.1848

Lawrie, S. M., Buechel, C., Whalley, H. C., Frith, C. D., Friston, K. J., and Johnstone, E. C. (2002). Reduced frontotemporal functional connectivity in schizophrenia associated with auditory hallucinations. Biol. Psychiatry 51, 1008-1011. doi: 10. 1016/s0006-3223(02)01316-1

Lee, P. R., Brady, D. L., Shapiro, R. A., Dorsa, D. M., and Koenig, J. I. (2007). Prenatal stress generates deficits in rat social behavior: reversal by oxytocin. Brain Res. 1156, 152-167. doi: 10.1016/j.brainres.2007.04.042

Legault, M., Rompre, P. P., and Wise, R. A. (2000). Chemical stimulation of the ventral hippocampus elevates nucleus accumbens dopamine by activating dopaminergic neurons of the ventral tegmental area. J. Neurosci. 20, 16351642.

Lewis, M. C., and Gould, T. J. (2007). Reversible inactivation of the entorhinal cortex disrupts the establishment and expression of latent inhibition of cued fear conditioning in C57BL/6 mice. Hippocampus 17, 462-470. doi: 10.1002/hipo. 20284

Lewis, D. A., and Levitt, P. (2002). Schizophrenia as a disorder of neurodevelopment. Annu. Rev. Neurosci. 25, 409-432. doi: 10.1146/annurev.neuro.25.112701. 142754

Libby, L. A., Yonelinas, A. P., Ranganath, C., and Ragland, J. D. (2013). Recollection and familiarity in schizophrenia: a quantitative review. Biol. Psychiatry 73, 944950. doi: 10.1016/j.biopsych.2012.10.027

Lipska, B. K. (2004). Using animal models to test a neurodevelopmental hypothesis of schizophrenia. J. Psychiatry Neurosci. 29, 282-286.

Lipska, B. K., Halim, N. D., Segal, P. N., and Weinberger, D. R. (2002). Effects of reversible inactivation of the neonatal ventral hippocampus on behavior in the adult rat. J. Neurosci. 22, 2835-2842.

Lipska, B. K., Jaskiw, G. E., and Weinberger, D. R. (1993). Postpubertal emergence of hyperresponsiveness to stress and to amphetamine after neonatal excitotoxic hippocampal damage: a potential animal model of schizophrenia. Neuropsychopharmacology 9, 67-75. doi: 10.1038/npp.1993.44

Lipska, B. K., and Weinberger, D. R. (1994). Subchronic treatment with haloperidol and clozapine in rats with neonatal excitotoxic hippocampal damage. Neuropsychopharmacology 10, 199-205. doi: 10.1038/npp.1994.22

Lipska, B. K., and Weinberger, D. R. (2000). To model a psychiatric disorder in animals: schizophrenia as a reality test. Neuropsychopharmacology 23, 223-239. doi: 10.1016/s0893-133x(00)00137-8

Lodge, D. J., and Grace, A. A. (2009). Gestational methylazoxymethanol acetate administration: a developmental disruption model of schizophrenia. Behav. Brain Res. 204, 306-312. doi: 10.1016/j.bbr.2009.01.031

Louilot, A., and Besson, C. (2000). Specificity of amygdalostriatal interactions in the involvement of mesencephalic dopaminergic neurons in affective perception. Neuroscience 96, 73-82. doi: 10.1016/s0306-4522(99)00530-8

Louilot, A., and Choulli, M. K. (1997). Asymmetrical increases in dopamine turnover in the nucleus accumbens and lack of changes in locomotor responses following unilateral dopaminergic depletions in the entorhinal cortex. Brain Res. 778, 150-157. doi: 10.1016/s0006-8993(97)01050-0

Louilot, A., Jeanblanc, J., Peterschmitt, Y., and Meyer, F. (2010). "Parahippocampal region-dopaminergic neuron relationships in latent inhibition," in Latent Inhibition: Cognition, Neuroscience and Applications to Schizophrenia, eds R. E. Lubow and I. Weiner (New York: Cambridge University Press), 319-341.

Louilot, A., and Le Moal, M. (1994). Lateralized interdependence between limbicotemporal and ventrostriatal dopaminergic transmission. Neuroscience 59, 495-500. doi: 10.1016/0306-4522(94)90171-6

Louilot, A., Le Moal, M., and Simon, H. (1989). Opposite influences of dopaminergic pathways to the prefrontal cortex or the septum on the dopaminergic transmission in the nucleus accumbens. An in vivo voltammetric study. Neuroscience 29, 45-56. doi: 10.1016/0306-4522(89)90331-x

Lubow, R. E. (1989). Latent Inhibition and Conditioned Attention Theory. New York: Cambridge University Press.

Lubow, R. E., Kaplan, O., Abramovich, P., Rudnick, A., and Laor, N. (2000). Visual search in schizophrenia: latent inhibition and novel pop-out effects. Schizophr. Res. 45, 145-156. doi: 10.1016/s0920-9964(99)00188-7

Lubow, R. E., and Moore, A. U. (1959). Latent inhibition: the effect of nonreinforced pre-exposure to the conditional stimulus. J. Comp. Physiol. Psychol. 52, 415-419. doi: 10.1037/h0046700

Lubow, R. E., and Weiner, I. (2010). Latent Inhibition: Cognition, Neuroscience and Applications to Schizophrenia. New York: Cambridge University Press.

Mackintosh, N. J. (1975). A theory of attention: variations in the associability of stimuli with reinforcement. Psychol. Rev. 82, 276-298. doi: 10.1037/h00 76778 
Mackintosh, N. J. (1983). Conditioning and Associative Learning. Oxford: Oxford University Press.

McEvoy, J. P. (2007). The costs of schizophrenia. J. Clin. Psychiatry 68(Suppl. 14), 4-7.

McGeorge, A. J., and Faull, R. L. (1989). The organization of the projection from the cerebral cortex to the striatum in the rat. Neuroscience 29, 503-537. doi: 10 . 1016/0306-4522(89)90128-0

McIntosh, A. L., Ballard, T. M., Steward, L. J., Moran, P. M., and Fone, K. C. (2013). The atypical antipsychotic risperidone reverses the recognition memory deficits induced by post-weaning social isolation in rats. Psychopharmacology (Berl) 228, 31-42. doi: 10.1007/s00213-013-3011-2

Meltzer, H. Y., and Stahl, S. M. (1976). The dopamine hypothesis of schizophrenia: a review. Schizophr. Bull. 2, 19-76. doi: 10.1093/schbul/2.1.19

Menon, V., Anagnoson, R. T., Glover, G. H., and Pfefferbaum, A. (2001). Functional magnetic resonance imaging evidence for disrupted basal ganglia function in schizophrenia. Am. J. Psychiatry 158, 646-649. doi: 10.1176/appi.ajp.158.4.646

Meyer, F. F., and Louilot, A. (2011). Latent inhibition-related dopaminergic responses in the nucleus accumbens are disrupted following neonatal transient inactivation of the ventral subiculum. Neuropsychopharmacology 36, 1421-1432. doi: $10.1038 /$ npp. 2011.26

Meyer, F., and Louilot, A. (2012). Early prefrontal functional blockade in rats results in schizophrenia-related anomalies in behavior and dopamine. Neuropsychopharmacology 37, 2233-2243. doi: 10.1038/npp.2012.74

Meyer, F., Peterschmitt, Y., and Louilot, A. (2009). Postnatal functional inactivation of the entorhinal cortex or ventral subiculum has different consequences for latent inhibition-related striatal dopaminergic responses in adult rats. Eur. J. Neurosci. 29, 2035-2048. doi: 10.1111/j.1460-9568.2009.06755.x

Meyer, U. (2014). Prenatal poly(i:C) exposure and other developmental immune activation models in rodent systems. Biol. Psychiatry 75, 307-315. doi: 10.1016/j. biopsych.2013.07.011

Meyer-Lindenberg, A. (2010). From maps to mechanisms through neuroimaging of schizophrenia. Nature 468, 194-202. doi: 10.1038/nature09569

Miller, R. R., and Matzel, L. D. (1988). "The comparator hypothesis: a response rule for the expression of associations," in Psychology of Learning and Motivation, ed G. H. Bower (New-York: Academic Press), 51-92.

Miranda, M. I., and Bermúdez-Rattoni, F. (2007). Cholinergic activity in the insular cortex is necessary for acquisition and consolidation of contextual memory. Neurobiol. Learn. Mem. 87, 343-351. doi: 10.1016/j.nlm.2006.09.010

Mogenson, G. J., Swanson, L. W., and Wu, M. (1983). Neural projections from nucleus accumbens to globus pallidus, substantia innominata, and lateral preoptic-lateral hypothalamic area: an anatomical and electrophysiological investigation in the rat. J. Neurosci. 3, 189-202.

Montaron, M. F., Deniau, J. M., Menetrey, A., Glowinski, J., and Thierry, A. M. (1996). Prefrontal cortex inputs of the nucleus accumbens-nigro-thalamic circuit. Neuroscience 71, 371-382. doi: 10.1016/0306-4522(95)00455-6

Morari, M., Marti, M., Sbrenna, S., Fuxe, K., Bianchi, C., and Beani, L. (1998). Reciprocal dopamine-glutamate modulation of release in the basal ganglia. Neurochem. Int. 33, 383-397. doi: 10.1016/S0197-0186(98)00052-7

Murray, R. M., Lappin, J., and Di Forti, M. (2008). Schizophrenia: from developmental deviance to dopamine dysregulation. Eur. Neuropsychopharmacol. 18(Suppl. 3), S129-S134. doi: 10.1016/j.euroneuro.2008.04.002

Naber, P. A., Witter, M. P., and Lopes Silva, F. H. (2000). Networks of the hippocampal memory system of the rat. The pivotal role of the subiculum. Ann. N Y Acad. Sci. 911, 392-403. doi: 10.1111/j.1749-6632.2000.tb06739.x

Nesvåg, R., Bergmann, Ø., Rimol, L. M., Lange, E. H., Haukvik, U. K., Hartberg, C. B., et al. (2012). A 5-year follow-up study of brain cortical and subcortical abnormalities in a schizophrenia cohort. Schizophr. Res. 142, 209-216. doi: 10. 1016/j.schres.2012.10.004

O'Donnell, P. (2011). Adolescent onset of cortical disinhibition in schizophrenia: insights from animal models. Schizophr. Bull. 37, 484-492. doi: 10. 1093/schbul/sbr028

O'Mara, S. (2005). The subiculum: what it does, what it might do and what neuroanatomy has yet to tell us. J. Anat. 207, 271-282. doi: 10.1111/j.1469-7580. 2005.00446.x

Palaniyappan, L., Al-Radaideh, A., Mougin, O., Gowland, P., and Liddle, P. F. (2013). Combined white matter imaging suggests myelination defects in visual processing regions in schizophrenia. Neuropsychopharmacology 38, 1808-1815. doi: $10.1038 /$ npp. 2013.80
Palaniyappan, L., and Liddle, P. F. (2012). Aberrant cortical gyrification in schizophrenia: a surface-based morphometry study. J. Psychiatry Neurosci. 37, 399-406. doi: 10.1503/jpn.110119

Palmer, A. A., Printz, D. J., Butler, P. D., Dulawa, S. C., and Printz, M. P. (2004). Prenatal protein deprivation in rats induces changes in prepulse inhibition and NMDA receptor binding. Brain Res. 996, 193-201. doi: 10.1016/j.brainres.2003. 09.077

Peleg-Raibstein, D., and Feldon, J. (2006). Effects of dorsal and ventral hippocampal NMDA stimulation on nucleus accumbens core and shell dopamine release. Neuropharmacology 51, 947-957. doi: 10.1016/j.neuropharm.2006. 06.002

Pelletier, M., Achim, A. M., Montoya, A., Lal, S., and Lepage, M. (2005). Cognitive and clinical moderators of recognition memory in schizophrenia: a metaanalysis. Schizophr. Res. 74, 233-252. doi: 10.1016/j.schres.2004.08.017

Peterschmitt, Y., Hoeltzel, A., and Louilot, A. (2005). Striatal dopaminergic responses observed in latent inhibition are dependent on the hippocampal ventral subicular region. Eur. J. Neurosci. 22, 2059-2068. doi: 10.1111/j.14609568.2005.04366.x

Peterschmitt, Y., Meyer, F., and Louilot, A. (2007). Neonatal functional blockade of the entorhinal cortex results in disruption of accumbal dopaminergic responses observed in latent inhibition paradigm in adult rats. Eur. J. Neurosci. 25, 2504 2513. doi: 10.1111/j.1460-9568.2007.05503.x

Peterschmitt, Y., Meyer, F., and Louilot, A. (2008). Differential influence of the ventral subiculum on dopaminergic responses observed in core and dorsomedial shell subregions of the nucleus accumbens in latent inhibition. Neuroscience 154, 898-910. doi: 10.1016/j.neuroscience.2008.03.073

Petrulis, A., Alvarez, P., and Eichenbaum, H. (2005). Neural correlates of social odor recognition and the representation of individual distinctive social odors within entorhinal cortex and ventral subiculum. Neuroscience 130, 259-274. doi: 10. 1016/j.neuroscience.2004.09.001

Phillips, P. E., Stuber, G. D., Heien, M. L., Wightman, R. M., and Carelli, R. M. (2003). Subsecond dopamine release promotes cocaine seeking. Nature 422, 614-618. doi: 10.1038/nature01476

Powell, S. B. (2010). Models of neurodevelopmental abnormalities in schizophrenia. Curr. Top. Behav. Neurosci. 4, 435-481. doi: 10.1007/7854_2010_57

Powell, S. B., Zhou, X., and Geyer, M. A. (2009). Prepulse inhibition and genetic mouse models of schizophrenia. Behav. Brain Res. 204, 282-294. doi: 10.1016/j. bbr.2009.04.021

Prasad, K. M., Patel, A. R., Muddasani, S., Sweeney, J., and Keshavan, M. S. (2004). The entorhinal cortex in first-episode psychotic disorders: a structural magnetic resonance imaging study. Am. J. Psychiatry 161, 1612-1619. doi: 10.1176/appi. ajp.161.9.1612

Rapoport, J. L., Giedd, J. N., and Gogtay, N. (2012). Neurodevelopmental model of schizophrenia: update 2012. Mol. Psychiatry 17, 1228-1238. doi: 10.1038/mp. 2012.23

Rascle, C., Mazas, O., Vaiva, G., Tournant, M., Raybois, O., Goudemand, M., et al. (2001). Clinical features of latent inhibition in schizophrenia. Schizophr. Res. 51, 149-161. doi: 10.1016/s0920-9964(00)00162-6

Rehn, A. E., and Rees, S. M. (2005). Investigating the neurodevelopmental hypothesis of schizophrenia. Clin. Exp. Pharmacol. Physiol. 32, 687-696. doi: 10.1111/j. 1440-1681.2005.04257.x

Rosoklija, G., Toomayan, G., Ellis, S. P., Keilp, J., Mann, J. J., Latov, N., et al. (2000). Structural abnormalities of subicular dendrites in subjects with schizophrenia and mood disorders: preliminary findings. Arch. Gen. Psychiatry 57, 349-356. doi: 10.1001/archpsyc.57.4.349

Sawa, A., and Snyder, S. H. (2002). Schizophrenia: diverse approaches to a complex disease. Science 296, 692-695. doi: 10.1126/science.1070532

Schlessinger, A. R., Cowan, W. M., and Gottlieb, D. I. (1975). An autoradiographic study of the time of origin and the pattern of granule cell migration in the dentate gyrus of the rat. J. Comp. Neurol. 159, 149-175. doi: 10.1002/cne. 901590202

Schmitt, A., Hasan, A., Gruber, O., and Falkai, P. (2011). Schizophrenia as a disorder of disconnectivity. Eur. Arch. Psychiatry Clin. Neurosci. 261(Suppl. 2), S150S154. doi: 10.1007/s00406-011-0242-2

Schneider, M., and Koch, M. (2003). Chronic pubertal, but not adult chronic cannabinoid treatment impairs sensorimotor gating, recognition memory and the performance in a progressive ratio task in adult rats. Neuropsychopharmacology 28, 1760-1769. doi: 10.1038/sj.npp.1300225 
Schneider, M., and Koch, M. (2005). Behavioral and morphological alterations following neonatal excitotoxic lesions of the medial prefrontal cortex in rats. Exp. Neurol. 195, 185-198. doi: 10.1016/j.expneurol.2005.04.014

Schwabe, K., Enkel, T., Klein, S., Schutte, M., and Koch, M. (2004). Effects of neonatal lesions of the medial prefrontal cortex on adult rat behaviour. Behav. Brain Res. 153, 21-34. doi: 10.1016/j.bbr.2003.10.030

Schwabe, K., Klein, S., and Koch, M. (2006). Behavioural effects of neonatal lesions of the medial prefrontal cortex and subchronic pubertal treatment with phencyclidine of adult rats. Behav. Brain Res. 168, 150-160. doi: 10.1016/j.bbr. 2005.11.005

Sesack, S. R., and Pickel, V. M. (1992). Prefrontal cortical efferents in the rat synapse on unlabeled neuronal targets of catecholamine terminals in the nucleus accumbens septi and on dopamine neurons in the ventral tegmental area. $J$. Comp. Neurol. 320, 145-160. doi: 10.1002/cne.903200202

Shi, F., Yap, P. T., Gao, W., Lin, W., Gilmore, J. H., and Shen, D. (2012). Altered structural connectivity in neonates at genetic risk for schizophrenia: a combined study using morphological and white matter networks. Neuroimage 62, 1622 1633. doi: 10.1016/j.neuroimage.2012.05.026

Singh, S. C. (1977a). Comparison of electron microscopy and silver staining for the detection of the first entorhinal synapses to develop in the dentate gyrus. Anat. Embryol. (Berl) 151, 71-79. doi: 10.1007/bf00315299

Singh, S. C. (1977b). The development of olfactory and hippocampal pathways in the brain of the rat. Anat. Embryol. (Berl) 151, 183-199. doi: 10.1007/bf00 297480

Spitzer, N. C. (2006). Electrical activity in early neuronal development. Nature 444, 707-712. doi: 10.1038/nature05300

Stephan, K. E., Baldeweg, T., and Friston, K. J. (2006). Synaptic plasticity and dysconnection in schizophrenia. Biol. Psychiatry 59, 929-939. doi: 10.1016/j. biopsych.2005.10.005

Stephan, K. E., Friston, K. J., and Frith, C. D. (2009). Dysconnection in schizophrenia: from abnormal synaptic plasticity to failures of self-monitoring. Schizophr. Bull. 35, 509-527. doi: 10.1093/schbul/sbn176

Stevens, M., Peigneur, S., and Tytgat, J. (2011). Neurotoxins and their binding areas on voltage-gated sodium channels. Front. Pharmacol. 2:71. doi: 10.3389/fphar. 2011.00071

Stryker, M. P., and Harris, W. A. (1986). Binocular impulse blockade prevents the formation of ocular dominance columns in cat visual cortex. J. Neurosci. 6, 2117-2133.

Suzuki, W. A., and Eichenbaum, H. (2000). The neurophysiology of memory. Ann. N Y Acad. Sci. 911, 175-191. doi: 10.1111/j.1749-6632.2000.tb06726.x

Swerdlow, N. R. (2010). "A cautionary note about latent inhibition in schizophrenia: are we ignoring relevant information?" in Latent Inhibition: Cognition, Neuroscience and Applications to Schizophrenia, eds R. E. Lubow and I. Weiner (New York: Cambridge University Press), 448-456.

Taber, M. T., and Fibiger, H. C. (1993). Electrical stimulation of the medial prefrontal cortex increases dopamine release in the striatum. Neuropsychopharmacology 9, 271-275. doi: 10.1038/npp.1993.63

Totterdell, S., and Meredith, G. E. (1997). Topographical organization of projections from the entorhinal cortex to the striatum of the rat. Neuroscience 78, 715729. doi: 10.1016/s0306-4522(96)00592-1

Tseng, K. Y., Chambers, R. A., and Lipska, B. K. (2009). The neonatal ventral hippocampal lesion as a heuristic neurodevelopmental model of schizophrenia. Behav. Brain Res. 204, 295-305. doi: 10.1016/j.bbr.2008.11.039

Usun, Y., Eybrard, S., Meyer, F., and Louilot, A. (2013). Ketamine increases striatal dopamine release and hyperlocomotion in adult rats after postnatal functional blockade of the prefrontal cortex. Behav. Brain Res. 256, 229-237. doi: 10.1016/j. bbr.2013.08.017

van Eden, C. G., Kros, J. M., and Uylings, H. B. (1990). The development of the rat prefrontal cortex. Its size and development of connections with thalamus, spinal cord and other cortical areas. Prog. Brain Res. 85, 169-183. doi: 10.1016/S00796123(08)62680-1

van Erp, T. G., Lesh, T. A., Knowlton, B. J., Bearden, C. E., Hardt, M., Karlsgodt, K. H., et al. (2008). Remember and know judgments during recognition in chronic schizophrenia. Schizophr. Res. 100, 181-190. doi: 10.1016/j.schres.2007. 09.021
Van Groen, T., and Lopes da Silva, F. H. (1986). Organization of the reciprocal connections between the subiculum and the entorhinal cortex in the cat: II. An electrophysiological study. J. Comp. Neurol. 251, 111-120. doi: 10.1002/cne. 902510108

van Groen, T., Miettinen, P., and Kadish, I. (2003). The entorhinal cortex of the mouse: organization of the projection to the hippocampal formation. Hippocampus 13, 133-149. doi: 10.1002/hipo.10037

Voorn, P., Vanderschuren, L. J., Groenewegen, H. J., Robbins, T. W., and Pennartz, C. M. (2004). Putting a spin on the dorsal-ventral divide of the striatum. Trends Neurosci. 27, 468-474. doi: 10.1016/j.tins.2004.06.006

Wagner, A. R. (1976). "Priming in STM: an information processing mechanism for self-generated or retrieval-generated depression in performance," in Habituation: Perspectives from Child Development, Animal Behavior and Neurophysiology, eds T. Tighe and R. N. Leaton (Hillsdale, NJ: Lawrence Erlbaum), 95-128.

Wang, H., and Pickel, V. M. (2002). Dopamine D2 receptors are present in prefrontal cortical afferents and their targets in patches of the rat caudateputamen nucleus. J. Comp. Neurol. 442, 392-404. doi: 10.1002/cne.10086

Weinberger, D. R. (1996). On the plausibility of "the neurodevelopmental hypothesis" of schizophrenia. Neuropsychopharmacology 14, 1S-11S. doi: 10.1016/0893$133 x(95) 00199-n$

Weinberger, D. R., Aloia, M. S., Goldberg, T. E., and Berman, K. F. (1994). The frontal lobes and schizophrenia. J. Neuropsychiatry Clin. Neurosci. 6, 419-427.

Weinberger, D. R., and Lipska, B. K. (1995). Cortical maldevelopment, antipsychotic drugs, and schizophrenia: a search for common ground. Schizophr. Res. 16, 87-110. doi: 10.1016/0920-9964(95)00013-c

Weiner, I. (1990). Neural substrates of latent inhibition: the switching model. Psychol. Bull. 108, 442-461. doi: 10.1037//0033-2909.108.3.442

Weiner, I. (2003). The "two-headed" latent inhibition model of schizophrenia: modeling positive and negative symptoms and their treatment. Psychopharmacology (Berl) 169, 257-297. doi: 10.1007/s00213-002-1313-x

Weiner, I., and Feldon, J. (1997). The switching model of latent inhibition: an update of neural substrates. Behav. Brain Res. 88, 11-25. doi: 10.1016/s01664328(97)02314-0

Wright, C. I., and Groenewegen, H. J. (1995). Patterns of convergence and segregation in the medial nucleus accumbens of the rat: relationships of prefrontal cortical, midline thalamic, and basal amygdaloid afferents. J. Comp. Neurol. 361, 383-403. doi: 10.1002/cne.903610304

Yang, Y., Fung, S. J., Rothwell, A., Tianmei, S., and Weickert, C. S. (2011). Increased interstitial white matter neuron density in the dorsolateral prefrontal cortex of people with schizophrenia. Biol. Psychiatry 69, 63-70. doi: 10.1016/j.biopsych. 2010.08.020

Young, A. M., Moran, P. M., and Joseph, M. H. (2005). The role of dopamine in conditioning and latent inhibition: what, when, where and how? Neurosci. Biobehav. Rev. 29, 963-976. doi: 10.1016/j.neubiorev.2005.02.004

Zahm, D. S. (2000). An integrative neuroanatomical perspective on some subcortical substrates of adaptive responding with emphasis on the nucleus accumbens. Neurosci. Biobehav. Rev. 24, 85-105. doi: 10.1016/s0149-7634(99)00065-2

Conflict of Interest Statement: The authors declare that the research was conducted in the absence of any commercial or financial relationships that could be construed as a potential conflict of interest.

Received: 22 November 2013; accepted: 21 March 2014; published online: 07 April 2014.

Citation: Meyer F and Louilot A (2014) Consequences at adulthood of transient inactivation of the parahippocampal and prefrontal regions during early development: new insights from a disconnection animal model for schizophrenia. Front. Behav. Neurosci. 8:118. doi: 10.3389/fnbeh.2014.00118

This article was submitted to the journal Frontiers in Behavioral Neuroscience. Copyright (C) 2014 Meyer and Louilot. This is an open-access article distributed under the terms of the Creative Commons Attribution License (CC BY). The use, distribution or reproduction in other forums is permitted, provided the original author (s) or licensor are credited and that the original publication in this journal is cited, in accordance with accepted academic practice. No use, distribution or reproduction is permitted which does not comply with these terms. 